\title{
Modulation of skin cell functions by transforming growth factor- $\beta 1$ and ACTH after ultraviolet irradiation
}

\author{
N S Dissanayake and R S Mason \\ Department of Physiology, University of Sydney, New South Wales 2006, Australia \\ (Requests for offprints should be addressed to R S Mason)
}

\begin{abstract}
The adaptive responses in skin to ultraviolet (UV) radiation include increased cornification of keratinocytes and increased synthesis and distribution of melanin by melanocytes.

The possible involvement of paracrine factors in the generation of these responses was studied in a novel twostage culture model. Human melanocytes or keratinocytes were first irradiated or sham-irradiated and then the conditioned media collected from these cells after $24 \mathrm{~h}$ were used to treat unirradiated skin cells.

Immunofluorescent staining for transforming growth factor (TGF)- $\beta 1$ was increased in UV-irradiated keratinocytes compared with sham-irradiated cells. Increased TGF- $\beta 1$ was also detected in the culture media of irradiated keratinocytes. Treatment of unirradiated keratinocytes with conditioned media collected from UVirradiated keratinocytes resulted in increased absolute numbers and percentages of cornified envelopes per well compared with treatment with conditioned media from sham-irradiated keratinocytes. The magnitude of this
\end{abstract}

effect increased with increased dose of initial irradiation. The effects of conditioned media from UVR-treated cells were mimicked by authentic TGF- $\beta 1$. Treatment of conditioned media from irradiated cells with an antibody shown to neutralise the effects of TGF- $\beta 1$ but not with a non-immune antibody of similar isotype, abolished this bioactivity of the conditioned media from UV-irradiated cells. Immunofluorescent staining for ACTH was also increased in UV-irradiated keratinocytes. Conditioned media from UV-irradiated keratinocytes increased tyrosinase activity of unirradiated melanocytes, an effect which was mimicked by authentic ACTH. This bioactivity of conditioned media from irradiated keratinocytes was abolished in the presence of an antibody which neutralised the activity of ACTH but not MSH. These results provide evidence to support the involvement of TGF- $\beta 1$ and ACTH in the cornification and pigmentary responses respectively of skin cells after UV exposure.

Journal of Endocrinology (1998) 159, 153-163

\section{Introduction}

Exposure to ultraviolet (UV) irradiation results in a number of responses in irradiated skin which may be considered adaptive, that is, they are likely to provide some protection against further UV damage (Fitzpatrick 1986). These responses include increased thickness of the stratum corneum (cornification) (Fitzpatrick 1986) and increased pigment production and distribution (Szabo et al. 1982, Pawelek et al. 1992). Whilst some of the cellular changes are likely to be the result of direct interaction with UV, for instance through DNA (Gange et al. 1985, Gilchrest et al. 1993, Robert et al. 1996), it is likely that locally released agents, acting in a paracrine or endocrine manner, contribute to the observed responses.

Indeed, there is some evidence that altered cellular function may be found in sites that are not subject to direct irradiation, suggesting the involvement of humoral factors. Stierner et al. (1989) reported increased numbers of melanocytes in UVB-exposed as well as shielded skin of human volunteers. Rosdahl (1979) also described increased melanocyte cell numbers in the shielded ears of mice after exposure of the other ear to UVB radiation. Conditioned media obtained from keratinocytes after exposure to UVB or UVA suppressed the induction of delayed hypersensitivity in mice (Swartz 1984, Aubin et al. 1991). These studies indicate that, apart from local effects, there is a possibility that some factors are released from irradiated cells into the circulation. Nevertheless, most released factors are likely to act mainly in a paracrine manner to modulate skin cell function after UV irradiation. Certainly, paracrine modulation of skin cell function has been documented under basal conditions (Halaban et al. 1988, Gordon et al. 1989, Archambault et al. 1995).

Although a large number of hormones, growth factors and cytokines are known to be released by skin cells as a result of solar irradiation, their subsequent involvement in 
the responses to this irradiation is somewhat speculative (Halaban et al. 1988, Kupper et al. 1989, Luger 1989, Kock et al. 1990, Kramer et al. 1993). To study this problem, a two-stage model using cultured skin cells was developed. In the first step of this model, human keratinocytes or melanocytes were subjected to UV irradiation of various types and the direct effects on cell proliferation, cornification and pigmentation were measured (Dissanayake et al. 1993). In the second stage, conditioned media were collected from irradiated skin cells and used to treat unirradiated skin cells in an attempt to determine whether any of the adaptive responses such as increased cornification of keratinocytes or increased pigmentary activity of melanocytes could be induced by this conditioned media.

Our results indicate that adaptive responses could indeed be induced by conditioned media and provide some evidence for the involvement of transforming growth factor beta 1 (TGF- $\beta 1$ ) and adrenocorticotrophin (ACTH) in these processes.

\section{Materials and Methods}

\section{Materials}

Standard cell culture materials were obtained from CytoSystems (Sydney, Australia), Sigma Chemical Company (St Louis, MO, USA) and CSL (Sydney, Australia) as previously described (Dissanayake et al. 1993, McLeod et al. 1995). L- $\left[3,5-{ }^{3} \mathrm{H}\right]$ Tyrosine and [methyl${ }^{3} \mathrm{H}$ ]thymidine were obtained from Amersham Australia Pty Ltd (Sydney, Australia). Extracellular matrix (ECM)coated tissue culture plates were purchased from Cell Dynamics (Sydney, Australia). Ultima Gold scintillant was purchased from Packard Australia (Sydney, Australia).

Human ACTH (1-39), alpha melanocyte-stimulating hormone $(\alpha M S H)$ and TGF- $\beta 1$ from human platelets were obtained from Sigma Chemical Company. AntiTGF- $\beta 1$ (monoclonal, immunoglobulin (Ig) Y) neutralising antibody raised in chickens and a non-immune antibody of similar isotype were purchased from Immuno Diagnostics (R \& D Systems, Minneapolis, MN, USA). The TGF- $\beta 1$ antibody neutralised $100 \%$ of the bioactivity of human TGF- $\beta 1$ but not that of human TGF- $\beta 2$ and was stated to have no cross-reactivity with fibroblast growth factor, human platelet-derived growth factor, human interleukin (IL)- $\alpha$, IL-1 $\beta$, IL-2, IL-3, IL-4, IL-6, IL-7, tumour necrosis factor (TNF)- $\alpha$, TNF- $\beta$, GMcolony-stimulating factor (CSF), or G-CSF as determined by enzyme-linked immunosorbent assay. Fluorescein isothiocyanate (FITC)-labelled sheep anti-rabbit IgG was purchased from Silenus Laboratories (Sydney, Australia). Anti-TGF- $\beta 1$ (polyclonal) was from Sigma Chemical Company. ACTH antibody ( $\operatorname{IgG})$ specific for residues 18-25 of human ACTH (1-39) used for immunohistochemistry studies and Western blot was supplied by
Dr Jean Joss of Macquarie University, Sydney (Joss et al. 1990). Nonimmune IgG antibody was purchased from Sigma Chemical Company.

\section{Culture of melanocytes}

Human melanocytes were cultured as previously described by Ranson et al. (1988). In brief, cultures were routinely maintained in melanocyte growth medium (MGM) which consists of Essential Minimum Eagle Medium (EMEM) with $2 \mathrm{mM}$ glutamine, $0.01 \mathrm{mM}$ non-essential amino acids, $5 \%(\mathrm{v} / \mathrm{v})$ heat inactivated fetal calf serum (FCS), 10 $\mathrm{nM}$ cholera toxin and 16-32 nM phorbol 12-myristate13-acetate (PMA), $\mathrm{pH} 7 \cdot 2$. Prior to experiments, melanocytes were plated onto ECM-coated multiwell dishes in melanocyte growth medium and were maintained without PMA or cholera toxin for $48 \mathrm{~h}$ (Ranson et al. 1988, McLeod et al. 1995).

\section{Culture of keratinocytes}

Human keratinocytes from neonatal foreskins were propagated in keratinocyte growth medium which consists of Dulbecco's modification of Eagle's Medium (DMEM) base medium with $0.3 \mathrm{mM} \mathrm{Ca}^{++} \mathrm{pH} 7.4$ with the following additives: $10 \%(\mathrm{v} / \mathrm{v})$ heat inactivated FCS, $2 \cdot 2 \mathrm{~g} / 1 \mathrm{NaHCO}_{3}, 10 \mathrm{mM}$ HEPES buffer, $10 \mathrm{ng} / \mathrm{ml}$ epidermal growth factor, $0.5 \mu \mathrm{g} / \mathrm{ml}$ hydrocortisone and $10^{-10}$ M cholera toxin, penicillin $30 \mathrm{mg} / \mathrm{l}$, and streptomycin $50 \mathrm{mg} / \mathrm{l}$, as previously described (Dissanayake et al. 1993).

\section{UV sources}

As a source of UV irradiation, one FS20T12 UVB and one FL20SBL UVA (NSW Ultraviolet, Sydney, Australia) tube were mounted on a lamp housing. Two filters, cellulose acetate film and photocopier film (Celcast) were chosen in order to allow for transmission of predominantly UVA or mixed UVA $+B$ irradiation. These filters were subjected to transmission analysis using a Hitachi UV-VIS variable wavelength spectrophotometer (model 100-10). It was found that the cellulose acetate filter had very little transmission of wavelengths below $290 \mathrm{~nm}$ but transmitted $>80 \%$ at wavelengths above $310 \mathrm{~nm}$. The photocopier film showed no transmission below $310 \mathrm{~nm},<20 \%$ at $315 \mathrm{~nm}$ and $>50 \%$ above $325 \mathrm{~nm}$. Transmittance was also monitored after increased exposure to UVR and the filters were changed on a regular basis. The irradiance of the lamps with filters were measured with an IL 1700 Research Radiometer with tungsten calibration. Irradiances with the cellulose acetate filter were UVB 0.08 $\mathrm{mW} / \mathrm{cm}^{2}$ and UVA $0.20 \mathrm{~mW} / \mathrm{cm}^{2}$. With the photocopier film the corresponding values were UVB $0.002 \mathrm{~mW} / \mathrm{cm}^{2}$ and UVA $0.37 \mathrm{~mW} / \mathrm{cm}^{2}$. The solar simulator used in these experiments, which is comprised of a multiple lamp array configured to simulate the full spectrum of terrestrial 
sunlight at the equator at mid-summer noon and variable throughout each major spectral bandwidth, has previously been described in detail (Dissanayake et al. 1993). It should be noted that the use of the cellulose acetate filters with all UV sources mimics the action of natural atmospheric UV absorbers, but in so doing almost completely blocks the most biologically active wavelengths of the UV range, below $290 \mathrm{~nm}$, so that a relatively high total UVB dose is required for a biological effect.

\section{Irradiation of cells}

Second or third passage keratinocytes were used for the experiments. Keratinocytes were plated onto uncoated plastic in keratinocyte growth medium (KGM) and melanocytes were plated onto bovine corneal endothelialderived extracellular matrix-coated wells in MGM (Ranson et al. 1988, McLeod et al. 1995). Cells were irradiated $24 \mathrm{~h}$ after seeding. The doses of UV irradiation used in this study were based on our previous study (Dissanayake et al. 1993).

Before irradiation, the medium was aspirated and replaced with 3-4 drops of phosphate-buffered saline (PBS) (without calcium or magnesium). The appropriate filter was fitted and the cells were kept under the UV lamps or the solar simulator with the lid open. Immediately after the irradiation, the PBS was aspirated, $500 \mu \mathrm{l}$ growth medium was added into each well and the cells incubated for $24 \mathrm{~h}$ except where stated, before collection of conditioned media. Sham-irradiated cells were handled in an identical manner but were covered with black cardboard rather than the filters at the time of irradiation.

\section{Studies with conditioned medium}

After the irradiation, cells were incubated with KGM or MGM for $24 \mathrm{~h}$ unless otherwise stated. At the end of the incubation, conditioned media were collected into sterile tubes and stored in a $-80^{\circ} \mathrm{C}$ freezer until use. Unirradiated keratinocytes were seeded into $24-w e l l$ plates in KGM. Twenty-four hours after seeding, UV-conditioned medium was added to each well at a concentration of $30 \%$ $(\mathrm{v} / \mathrm{v})$ in a total volume of $1 \mathrm{ml}$. This concentration of conditioned medium had been shown in preliminary studies to produce maximal changes in the parameters measured in target cells. Cells were incubated with conditioned media for $36 \mathrm{~h}$. Conditioned medium from sham-irradiated cells was used at the same concentration as a control. Unirradiated melanocytes were plated on ECMcoated multiwell plates in MGM. Twenty-four hours after seeding, the medium was changed to growth medium without PMA or cholera toxin. After a further $48 \mathrm{~h}$, UV-conditioned medium was added to the cells at a concentration of $30 \%(\mathrm{v} / \mathrm{v})$ in a total volume of $1 \mathrm{ml}$ and the cells were incubated for $36 \mathrm{~h}$. Conditioned medium from sham-irradiated cells was used as a control.

\section{Antibody studies}

Test agents, TGF- $\beta 1, \mathrm{ACTH}$, and $\alpha \mathrm{MSH}$ were directly added in an aqueous vehicle. For studies with neutralising antibodies, the antigen and antibody were allowed to react in a small volume of culture media before being added to the cells. Similarly, UV-conditioned media or shamirradiated conditioned media were allowed to react with neutralising antibody before being added to the cells.

\section{Cell counts}

Cells were counted after detachment with trypsin in a haemocytometer or Model B Coulter counter (Coulter Electronics, Hialeah, FL, USA).

\section{Cornified envelopes}

Cornified envelope formation was measured according to the protocol of McLane et al. (1990). Cells were detached with trypsin and a known volume of cell suspension was dispensed into Eppendorf tubes and centrifuged. A solution of $2 \%$ sodium dodecyl sulphate and $10 \mathrm{mM}$ dithiothreitol was added to the cell pellets. After incubation at room temperature for $30 \mathrm{~min}$, cornified envelopes were counted in a haemocytometer.

\section{Tyrosinase activity}

Tyrosinase activity was measured in cell lysates by a modification of the method of Pomerantz (1966), as previously described by Ranson et al. (1988) and McLeod et al. (1995). Briefly, aliquots of cell lysate in sodium phosphate buffer ( $\mathrm{pH}$ 6.8) were incubated with $50 \mathrm{mM}$ dihydroxyphenylalanine (DOPA) and $\mathrm{L}-\left[3,5-{ }^{3} \mathrm{H}\right]$ tyrosine for $4 \mathrm{~h}$. At the end of the incubation, unreacted $\left[{ }^{3} \mathrm{H}\right]-$ tyrosine was removed by adsorption onto $10 \%$ (w/v) charcoal in $0 \cdot 1 \mathrm{M}$ citric acid followed by treatment with $50 \%(\mathrm{w} / \mathrm{v})$ Dowex resin solution. The supernatant containing $\left[{ }^{3} \mathrm{H}\right] \mathrm{H}_{2} \mathrm{O}$ was mixed with Ultima Gold scintillant and counted in a beta counter (Packard, Sydney, Australia).

\section{Immunofluorescence studies}

These experiments were carried out $24 \mathrm{~h}$ after UV irradiation. Following fixation of cells with methanol for $30 \mathrm{~s}$, cells were incubated in $3 \%(\mathrm{v} / \mathrm{v})$ goat serum in $0 \cdot 1 \%$ BSA in PBS for $30 \mathrm{~min}$ at $37^{\circ} \mathrm{C}$ to reduce non-specific staining. The cells were subsequently incubated overnight at $4{ }^{\circ} \mathrm{C}$ with TGF- $\beta 1(\operatorname{IgG})$ or ACTH (IgG) antibody, diluted in PBS, supplemented with $3 \%$ goat serum and $0 \cdot 1 \%$ BSA. The cells were then treated with a $1: 50$ dilution of anti-rabbit IgG-conjugated FITC for $1 \mathrm{~h}$ in the dark. All steps were separated by washes with PBS containing $0 \cdot 1 \%$ BSA. Finally, the cells were mounted in 
$3 \%$ glycerol in PBS. In control experiments, the TGF- $\beta 1$ or ACTH antibody was replaced with rabbit non-immune (similar isotype) $\operatorname{IgG}$.

\section{Immunoassays, Western blot and Northern blot analysis}

TGF- $\beta 1$ in cell culture conditioned media was measured by Predicta ELIZA kit (Genzyme Diagnostics, Cambridge, MA, USA) formulated for use with tissue culture media. According to the manufacturer, there was no significant cross-reactivity with TGF- $\beta 2$ or $-\beta 3$ and $6.9 \%$ cross-reactivity with TGF- $\beta 5$. A double antibody RIA kit (ICN Pharmaceuticals, Costa Mesa, CA, USA) was used in an attempt to measure ACTH in tissue culture media. Neither this kit, nor others available, were formulated for use with tissue culture media.

Proteins from lyophilised samples of culture media from sham- and UV-irradiated media were separated by SDS-PAGE and transferred to nitrocellulose by semi-dry electrophoresis. Blots were incubated with the ACTH antibody (Joss et al. 1990) and signals were detected using a ${ }^{125}$ I-labelled rabbit anti-mouse second antibody (New England Nuclear, Boston MA, USA). RNA was extracted from sham- and UV-irradiated keratinocytes, separated by electrophoresis and transferred to a nylon membrane (Genescreen, Dupont, Wilmington, DE, USA) by Northern blot as previously described (Nelson et al. 1996). The membranes were then hybridised with a cDNA probe to TGF- $\beta 1$ (ATCC, Rockville, MD, USA) and with a riboprobe to the housekeeping gene 36B4 (Chambon et al. 1984) and scanned using a Phosphor-Imager (Molecular Dynamics, Sunnyvale, CA, USA).

\section{Statistical methods}

Results are expressed as means \pm S.D. for cells from one donor or means \pm S.E. for pooled results from several donors. The means for each point for any one donor were generated from triplicate or quadruplicate determinations. The effects of treatments with one dependent variable such as the cell numbers per well were compared using Student's $t$-test for unpaired samples or where appropriate, a one-way analysis of variance coupled with a Ryans Q test. For tyrosinase activity, where results were corrected for cell numbers, the standard deviations of the ratios were calculated using the method of Colquhoun (1971) before application of the other tests.

\section{Results}

\section{Keratinocytes}

Incubation of unirradiated keratinocytes for $36 \mathrm{~h}$ with conditioned media (CM) collected from keratinocytes $24 \mathrm{~h}$ after exposure to solar-simulated irradiation
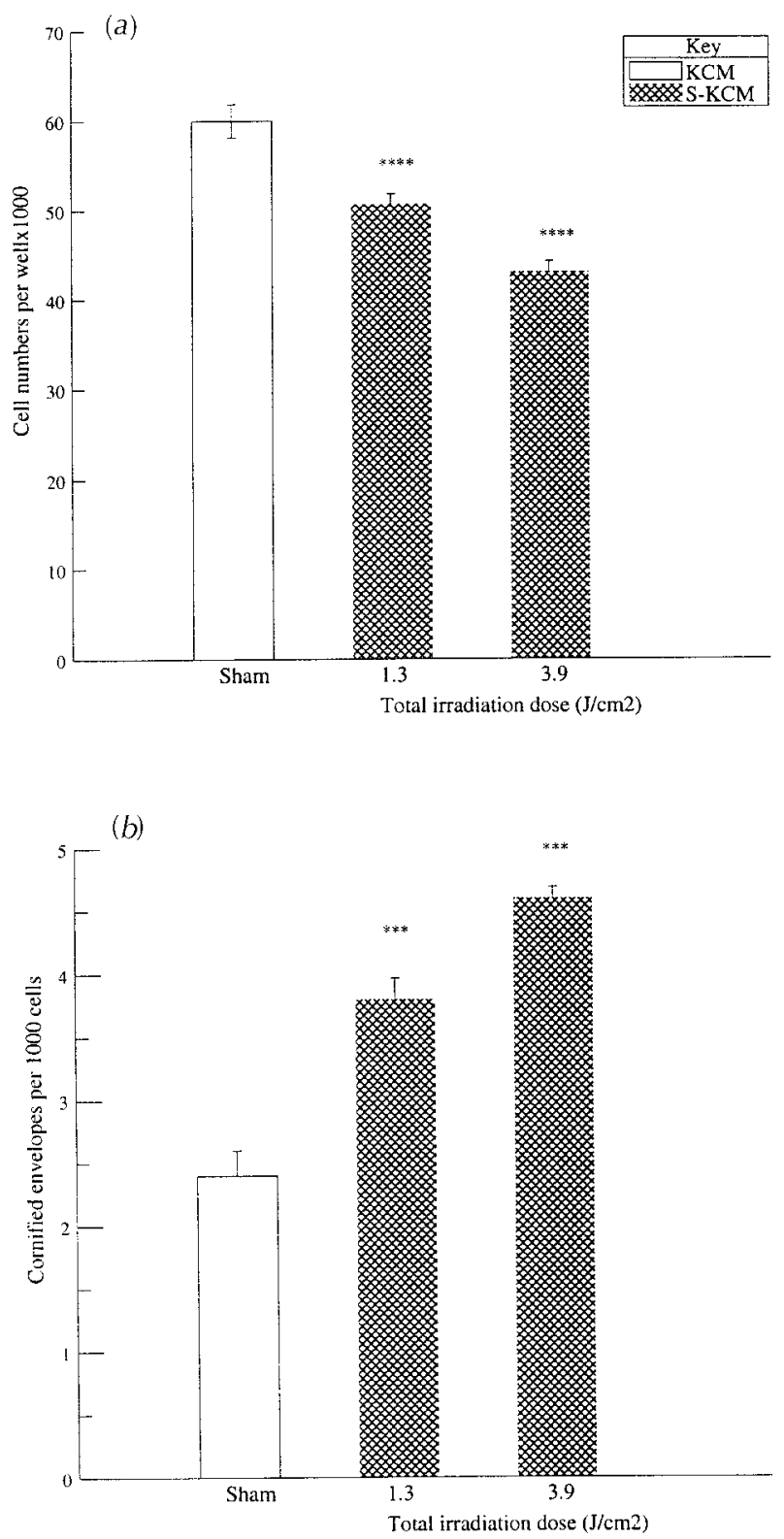

Figure 1 Effects of keratinocyte-conditioned media collected after solar-simulated irradiation (S-KCM) on cell numbers (a) or cornified envelope formation $(b)$ in unirradiated keratinocytes cultures. Cells were incubated with S-KCM for $36 \mathrm{~h}$. Absolute numbers of cornified envelopes per well were $146 \pm 18$ (Sham), $191 \pm 9\left(1.3 \mathrm{~J} / \mathrm{cm}^{2}\right)$, and $199 \pm 4\left(3.9 \mathrm{~J} / \mathrm{cm}^{2}\right)$. Values shown are means \pm S.D. of triplicate determinations. ${ }^{* *} P<0 \cdot 005,{ }^{* * *} P<0 \cdot 001$ compared with control keratinocytes incubated with sham-irradiated cells.

(S-KCM) resulted in a dose-dependent inhibition of keratinocyte cell numbers compared with control keratinocytes exposed to conditioned medium from shamirradiated cells (Fig. 1A). The cell numbers decreased to 
Table 1 Effects of conditioned media collected after UVA+B or UVA irradiation on keratinocyte cell numbers and cornified envelope formation. Values shown are the means \pm S.D. of triplicate determinations

\begin{tabular}{|c|c|c|}
\hline & $\begin{array}{l}\text { Cell numbers } \\
\text { per well }\end{array}$ & $\begin{array}{l}\text { Cornified envelopes } \\
\text { per well }\end{array}$ \\
\hline \multirow{2}{*}{\multicolumn{3}{|c|}{$\begin{array}{l}\text { UV treatment } \\
\left(\mathrm{mJ} / \mathrm{cm}^{2}\right)^{\mathrm{a}} \\
\text { UVB }\end{array}$}} \\
\hline & & \\
\hline Sham-irradiated & $35682 \pm 3153$ & $941 \pm 20$ \\
\hline 105 (filtered UVB) & $29670 \pm 1462 *$ & $1335 \pm 45^{\text {*** }}$ \\
\hline 210 (filtered UVB) & $21233 \pm 1294^{* * *}$ & $1735 \pm 39 * * *$ \\
\hline \multicolumn{3}{|l|}{ UVA } \\
\hline Sham-irradiated & $34666 \pm 1449$ & $864 \pm 38$ \\
\hline 1100 & $29050 \pm 1457^{* *}$ & $1118 \pm 108^{* *}$ \\
\hline 3400 & $22750 \pm 2182^{* * *}$ & $1631 \pm 20^{* * *}$ \\
\hline
\end{tabular}

aThe UV doses given in this table are the UV doses of irradiation given to keratinocytes from which conditioned media were collected. With the cellulose acetate filter, the filtered UVA doses for these cells were $240 \mathrm{~mJ} / \mathrm{cm}^{2}$ and $480 \mathrm{~mJ} / \mathrm{cm}^{2}$.

${ }^{*} P<0 \cdot 05 ;{ }^{* *} P<0 \cdot 01 ;{ }^{* * *} P<0 \cdot 005$, significantly different from control values.

$84 \pm 2 \% \quad(P<0 \cdot 001)$ of control after treatment with $\mathrm{S}-\mathrm{KCM}$ collected after $1.3 \mathrm{~J} / \mathrm{cm}^{2}$ total irradiation (which includes filtered UVB and UVA) and to $72 \pm 1.7 \%$ $(P<0 \cdot 001)$ of control with conditioned medium collected after $3.9 \mathrm{~J} / \mathrm{cm}^{2}$ irradiation. In a similar experiment repeated with cells from a different donor, the corresponding drops in cell numbers were to $84 \pm 11 \%(P<0 \cdot 001)$ and $69 \pm 4.5 \%(P<0 \cdot 001)$ of control respectively after treatment with $1.3 \mathrm{~J} / \mathrm{cm}^{2}$ and $3.9 \mathrm{~J} / \mathrm{cm}^{2} \mathrm{~S}-\mathrm{KCM}$. Of cell lines from 5 different donors, treatment with S-KCM $\left(3.9 \mathrm{~J} / \mathrm{cm}^{2}\right.$ caused an average drop in cell numbers to $82 \pm 6($ s.E. $) \%(P<0 \cdot 001)$ of control.

Exposure of unirradiated keratinocytes for $36 \mathrm{~h}$ to S-KCM stimulated cornified envelope formation (Fig. 1B). Incubation in conditioned media harvested from keratinocytes after exposure to $1.3 \mathrm{~J} / \mathrm{cm}^{2}$ solar-simulated irradiation increased cornified envelope formation to $150 \pm 16 \%(P<0 \cdot 01)$ of control while S-KCM $\left(3 \cdot 9 \mathrm{~J} / \mathrm{cm}^{2}\right)$ caused an increase to $167 \pm 12 \% \quad(P<0 \cdot 005)$. In cell lines from 4 different donors, an average increase in cornified envelopes to $207 \pm 17$ (s.E. $) \%(P<0 \cdot 005)$ of control was observed after treatment with S-KCM $\left(3.9 \mathrm{~J} / \mathrm{cm}^{2}\right)$.

Conditioned media collected from keratinocytes after exposure to UVA+B (UVA+B-KCM) or UVA (UVAKCM) produced similar effects when used to treat unirradiated keratinocytes (Table 1). Dose-dependent inhibition of unirradiated keratinocyte numbers was seen with conditioned media collected from cells exposed to either radiation type. Furthermore, dose-dependent increases in cornified envelope formation were observed when unirradiated keratinocytes were incubated with conditioned media collected after UVA $+B$ or UVA irradiation (Table 1).
Figure 2 demonstrates the immunofluorescence stain of keratinocytes for TGF- $\beta 1$. There is a clear, widespread staining for TGF- $\beta 1$ in UV-irradiated cells (a) compared with sham-irradiated cells $(c)$. Use of a non-specific antibody of a similar isotype to that of the TGF- $\beta 1$ antibody with this protocol resulted in little fluorescence background in irradiated or non-irradiated cells $(b$ and $d)$. Measured by ELIZA kit, TGF- $\beta 1$ in the culture media increased significantly with UV exposure in cultures from 3 separate donors. In one cell line, TGF- $\beta 1$ concentrations were $<0.1 \mathrm{ng} / \mathrm{ml}$ (limit of detection of assay) in media from sham-irradiated cells increasing to $0.17 \pm 0.04 \mathrm{ng} /$ $\mathrm{ml}$ after exposure to $25 \mathrm{~mJ} / \mathrm{cm}^{2}$ UVB and to $0 \cdot 25 \pm 0.02 \mathrm{ng} / \mathrm{ml}$ after $75 \mathrm{~mJ} / \mathrm{cm}^{2}$; in media from keratinocytes of a second donor, TGF- $\beta 1$ was again undetectable in sham-irradiated cultures but increased to $0.14 \pm 0.04 \mathrm{ng} / \mathrm{ml}$ after $50 \mathrm{~mJ} / \mathrm{cm}^{2}$ and to $0.5 \pm 0.03 \mathrm{ng} /$ $\mathrm{ml}$ after $100 \mathrm{~mJ} / \mathrm{cm}^{2} \mathrm{UVB}$. In the third cell strain there was a $2 \cdot 5$-fold increase from $0.29 \pm 0.06 \mathrm{ng} / \mathrm{ml}$ in shamirradiated cultures to $0.73 \pm 0.12 \mathrm{ng} / \mathrm{ml}$ after $100 \mathrm{~mJ} / \mathrm{cm}^{2}$ UVB. TGF- $\beta 1$ message was detected on Northern blots from both sham- and UV-irradiated keratinocytes from two cell strains. After correction for loading, however, no significant increase in TGF- $\beta 1$ message was seen in samples from irradiated cultures.

Since TGF- $\beta 1$ is known to increase cornified envelope formation (Reiss \& Sartorelli 1987) and since TGF- $\beta 1$ detection increased after UV irradiation, the effects of authentic TGF- $\beta 1$ alone on keratinocyte cell numbers and cornified envelope formation were tested. A concentration of $10 \mathrm{ng} / \mathrm{ml}$ TGF- $\beta 1$ was used in accord with previous work (Pietenpol et al. 1990). Cell numbers decreased by $25 \pm 5 \cdot 5 \% \quad(P<0 \cdot 005)$ while there was a $180 \pm 11 \%$ $(P<0 \cdot 005)$ increase in cornified envelope formation after incubation of keratinocytes with TGF- $\beta 1$ for $36 \mathrm{~h}$. These effects of TGF- $\beta 1$ on keratinocytes were abolished when the keratinocytes were incubated with both TGF- $\beta 1$ and an anti-TGF- $\beta 1$ neutralising antibody (control: cell numbers $83 \pm 9 \times 10^{3} /$ well, cornified envelopes $310 \pm 20 /$ well; TGF- $\beta 1$ : cell numbers $58 \pm 6 \times 10^{3} /$ well, cornified envelopes $557 \pm 33 /$ well; TGF- $\beta 1+$ antibody: cell numbers $83 \pm 5 \times 10^{3} /$ well, cornified envelopes $370 \pm 11 /$ well).

In view of these results, the UV-conditioned media were tested with an anti-TGF- $\beta 1$ neutralising antibody, to see whether the antibody would inhibit the bioactivity of UV-KCM. Cells were incubated with S-KCM alone or S-KCM with TGF- $\beta 1$ antibody for $36 \mathrm{~h}$ before assay. Growth medium and sham-irradiated conditioned medium were treated in a similar manner. As shown in Fig. 3 , the presence of TGF- $\beta 1$ antibody had no significant effect on cornified envelope formation in cells incubated in growth medium or media harvested from sham-irradiated cells. In contrast, the increase in cornified envelope formation noted in unirradiated keratinocytes incubated with S-KCM was abolished in the presence of 
(a)

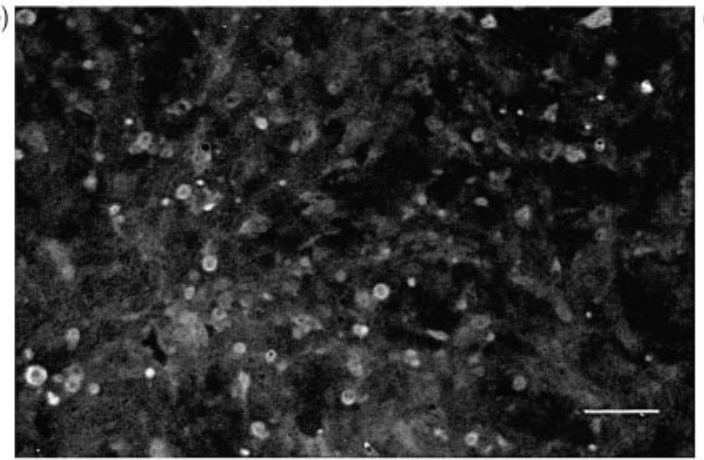

(c)

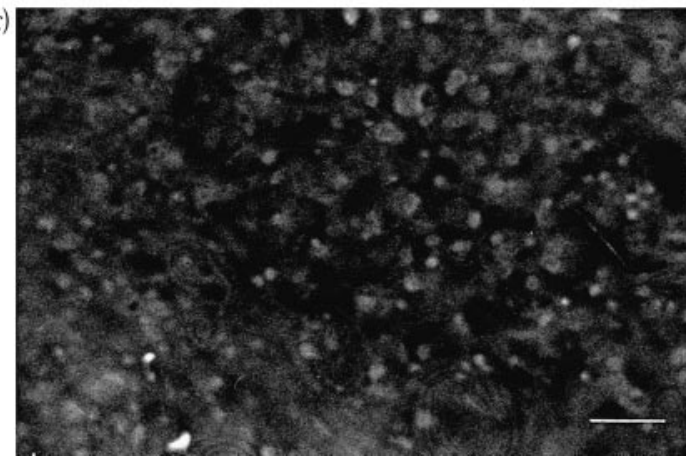

(b)

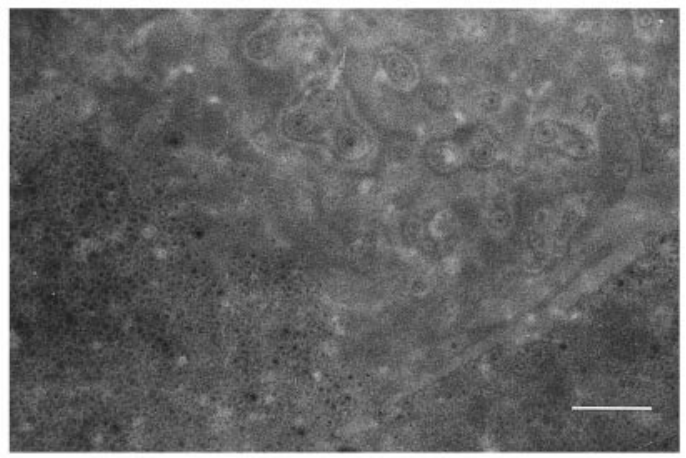

(d)



Figure 2 Direct immunofluorescent staining of keratinocytes for TGF- $\beta 1$ after exposure to UVR from a UVA+B source. (a) UV-irradiated keratinocytes stained with TGF- $\beta 1$ antibody. (b) UV-irradiated keratinocytes stained with a non-specific antibody of a similar isotype to the TGF- $\beta 1$ antibody. (c) Sham-irradiated keratinocytes stained for TGF- $\beta 1$.

(d) Sham-irradiated keratinocytes stained with a non-specific antibody of a similar isotype to the TGF- $\beta 1$ antibody. Original magnification $\times 100$. Scale bars represent $30 \mu \mathrm{m}$.

anti-TGF- $\beta 1$ neutralising antibody. Similarly, the presence of TGF- $\beta 1$ antibody had no effect on cell numbers incubated in growth medium or media harvested from sham-irradiated cells. In contrast an $84 \pm 3$ (s.D.)\% inhibition of cell numbers observed after treatment with S-KCM was abolished in the presence of anti-TGF- $\beta 1$ neutralising antibody. Similar results were also obtained in a second experiment using cells from a different donor. A nonimmune antibody of similar isotype to the TGF- $\beta 1$ antibody did not inhibit the bioactivity of UV-KCM on keratinocytes and had no significant effect on cell numbers or cornified envelope formation of keratinocytes in the presence of growth media or media from sham-irradiated cells.

\section{Melanocytes}

Incubation for $36 \mathrm{~h}$ with conditioned media harvested from keratinocytes or melanocytes $24 \mathrm{~h}$ after solar, UVA $+\mathrm{B}$ or UVA irradiation stimulated tyrosinase activity of melanocytes, compared with incubation with conditioned media from sham-irradiated cells (Table 2). In four different cell lines after treatment with S-KCM $\left(3 \cdot 9 \mathrm{~J} / \mathrm{cm}^{2}\right)$, the average increase in tyrosinase activity was
$151 \pm 16$ (S.E.) $\%(P<0 \cdot 005)$ of control. In two cell lines treated with CM from melanocytes irradiated with the solar simulator $\left(1.3 \mathrm{~J} / \mathrm{cm}^{2}\right)$, the average increase in tyrosinase activity was $134 \pm 18$ (range) $\%$.

Figure 4 illustrates staining for ACTH in sham- and UV-irradiated keratinocytes. A bright fluorescent staining of keratinocytes for ACTH was observed in UV-irradiated cells (a) compared with sham-irradiated cells $(c)$. Use of a non-specific antibody of a similar isotype to that of the ACTH antibody resulted in little fluorescence stain in irradiated or non-irradiated cells ( $b$ and $d$ ). Measurable concentrations of ACTH were not detected in culture media from sham- or UV-irradiated keratinocytes by commercial kits, although none were designed for use with tissue culture fluid, but ACTH was present by Western blot in culture media from both sham- and UV-irradiated keratinocytes.

In view of these results, unirradiated melanocytes were incubated with authentic ACTH. Incubation of melanocytes for $36 \mathrm{~h}$ with ACTH at a concentration of $10^{-10} \mathrm{M}$ (McLeod et al. 1995), resulted in an increase in tyrosinase activity from $133 \pm 10$ (counts per minute (c.p.m.) $/ 1000$ cells) to $210 \pm 21(P<0 \cdot 005)$. This stimulation of tyrosinase was abolished in the presence of an antibody to the 


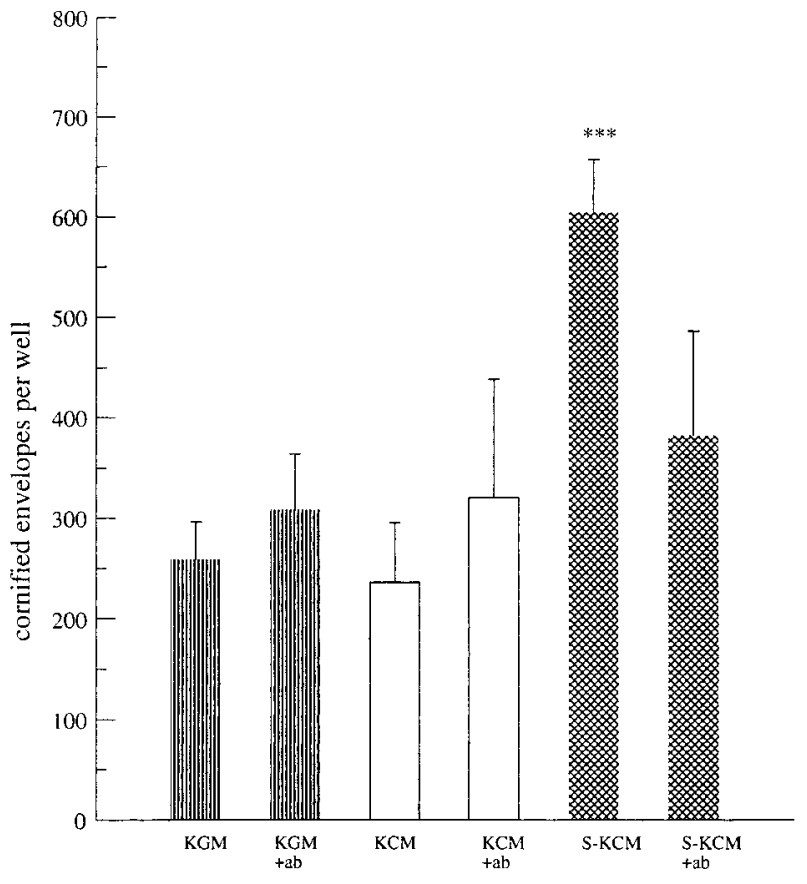

Figure 3 Neutralizing effect of antibody to TGF- $\beta 1$ on cornified envelope formation in unirradiated keratinocytes treated with S-KCM. Keratinocytes were incubated with keratinocyte growth medium (KGM), sham-irradiated conditioned medium (KCM) or solar-simulated conditioned medium (S-KCM) with or without antibody to TGF- $\beta 1$ (ab) for $36 \mathrm{~h}$ before the assay. Values shown are the means \pm S.D. of triplicate determinations. ${ }^{* *} P<0 \cdot 005$ compared with conditioned medium from sham-irradiated cells and from keratinocyte growth medium.

18-24 region of ACTH (147 \pm 16 c.p.m./1000 cells). The cross reactivity of the ACTH antibody to $\alpha \mathrm{MSH}$ was tested. Incubation of melanocytes for $72 \mathrm{~h}$ with $\alpha \mathrm{MSH}$ at a concentration of $10^{-6} \mathrm{M}$ (McLeod et al. 1995) caused a $127 \pm 18 \%$ increase in tyrosinase activity and the ACTH antibody $(\mathrm{Ab})$ failed to abolish this effect (MSH+ACTH Ab $132 \pm 8 \%$ of control, $P<0 \cdot 005)$.

When the neutralising antibody to ACTH was used with conditioned media from irradiated keratinocytes, the antibody had no effect on tyrosinase activity in the presence of melanocyte growth medium, had a small stimulatory effect on tyrosinase in the presence of conditioned medium from sham-irradiated keratinocytes, but it abolished the $230 \pm 24 \%(P<0 \cdot 001)$ stimulation of tyrosinase seen when these melanocytes were incubated with solar-KCM (Fig. 5). In a second experiment, using conditioned media from irradiated or sham-irradiated melanocytes, the anti-ACTH antibody abolished the small but significant increase in tyrosinase activity in melanocytes exposed to conditioned media from irradiated cells $(122 \pm 4 \%, P<0 \cdot 005)$. Use of a non-immune antibody of similar isotype to that of ACTH had no effect on bioactivity of UV-KCM in melanocytes.
Table 2 Effect of conditioned media collected after solar, UVA+B or UVA irradiation, on tyrosinase activity of melanocytes ${ }^{\mathrm{a}}$. Values shown are the means \pm S.D. of triplicate determinations

Tyrosinase activity

$(\% \text { of control })^{\mathrm{d}}$

$\begin{array}{ll}\begin{array}{l}\text { UV treatment } \\ \left(\mathrm{mJ} / \mathrm{cm}^{2}\right)^{\mathrm{b}}\end{array} \\ \text { UV-KCM } \\ \text { S-KCM (3900) } \\ \text { UVB-KCM (210) } \\ \text { UVA-KCM }(3400) & 229 \pm 2^{* * *} \\ \text { UV-MCM } & 115 \pm 2 \cdot 8^{*} \\ \text { S-MCM }(1300) & 177 \pm 23^{* * * *} \\ \text { UVB-MCM }(210)^{\mathrm{c}} & 158 \pm 23^{* *} \\ \text { UVA-MCM }(560) & 172 \pm 6^{* * *} \\ \text { UVA-MCM (3400) } & 141 \pm 7 \cdot 2^{* * *} \\ \end{array}$

${ }^{a}$ Melanocytes plated on ECM were maintained in the absence of PMA and cholera toxin for $48 \mathrm{~h}$ prior to the addition of UV conditioned media.

bThe UV doses given in this table are the UV doses of irradiation given to keratinocytes and melanocytes from which conditioned media were collected.

'With the cellulose acetate filter, the filtered UVA doses for these cells were $525 \mathrm{~mJ} / \mathrm{cm}^{2}$.

${ }^{\mathrm{d}}$ Control tyrosinase activities in cells from different donors ranged from 1676-2021 c.p.m/1000 cells/4 h.

${ }^{*} P<0 \cdot 05 ;{ }^{* *} P<0 \cdot 01 ;{ }^{* * *} P<0 \cdot 005 ;{ }^{* * * *} P<0 \cdot 001$, significantly different from control values.

\section{Discussion}

Ultraviolet radiation exposure produces thickening of the stratum corneum and increased melanin pigmentation in the skin, which act as two defensive barriers against further UVR damage (Gange et al. 1985, Fitzpatrick 1986). These effects have been well documented after direct exposure to UVR. The possible novel signal pathways that induce pigmentation after exposure to direct UVR have been addressed in recent years. Gilchrest et al. (1993) reported that when human melanocytes were treated with a DNA repair enzyme, $\mathrm{T} 4$ endonuclease $\mathrm{V}$, at the time of irradiation a marked increase in tyrosinase activity compared with control groups was noted. Involvement of protein kinase C-dependent pathways in increased melanogenesis has been described by Gordon and Gilchrest (1989), Park et al. (1993), McLeod et al. (1995) and Oka et al. (1996).

The idea that skin cells release soluble factors which have autocrine and paracrine effects has been described in previous studies (Rosdahl 1979, Halaban et al. 1988, Kupper et al. 1989, Kratz et al. 1991). Indeed a large number of growth factors and other cytokines have been shown to be released as a result of UVR (Swartz 1984, Kupper et al. 1989, Luger 1989, Aubin et al. 1991, Kramer et al. 1993). In this study, we extended these observations to show that conditioned media collected from irradiated skin cells were able to induce, in vitro, effects in unexposed skin cells which mimic the in vivo responses. Conditioned media harvested from keratinocytes after UV irradiation of 
(a)



(c)

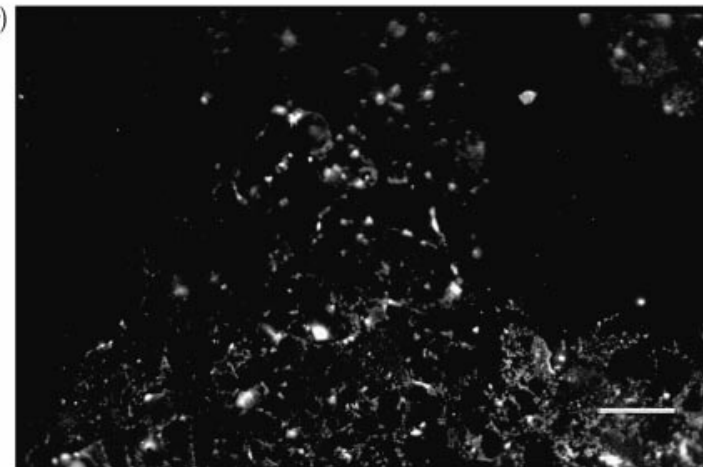

(b)

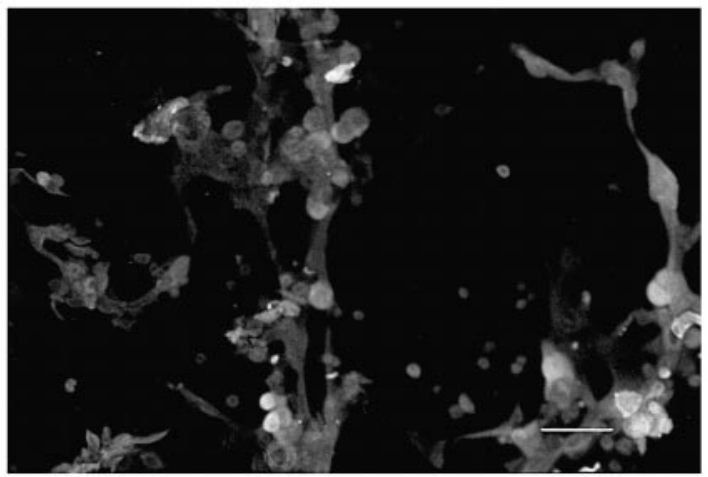

d)

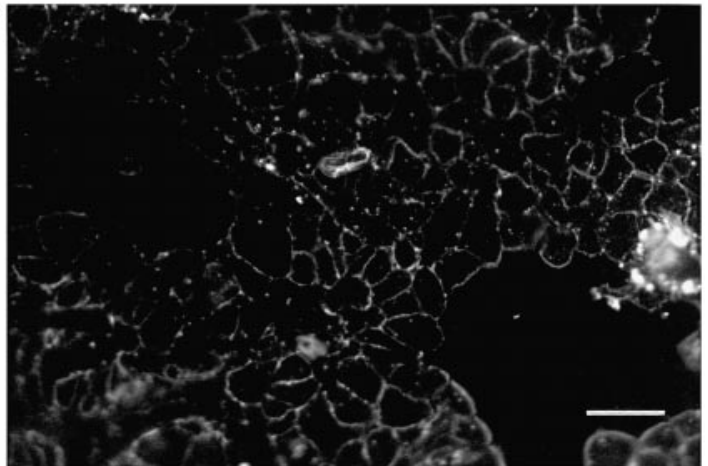

Figure 4 Direct immunofluorescent staining of keratinocytes for ACTH after exposure to UVR from an UVA+B source. (a) UV-irradiated keratinocytes stained with ACTH antibody. (b) UV-irradiated keratinocytes stained with a non-specific antibody of a similar isotype to that of the ACTH antibody. (c) Sham-irradiated keratinocytes stained for ACTH. (d) Sham-irradiated keratinocytes stained with a non-specific antibody of a similar isotype to that for ACTH. Original magnification $\times 100$. Scale bars represent $30 \mu \mathrm{m}$.

various types increased pigmentary activity of unirradiated melanocytes and increased cornification of unirradiated keratinocytes. Similarly, conditioned media harvested from UV-irradiated melanocytes increased tyrosinase activity of melanocytes.

Increased epidermal thickness following UV exposure is brought about partly by increased proliferation of keratinocytes and particularly by increases in the cornified layer (Fitzpatrick 1986). Even in the absence of melanocytes, vitiligous skin showed high values of sun protection factor after repeated exposure to UV radiation (Morison 1985). Whilst our model does not provide an explanation for the hyperproliferation of keratinocytes noted in vivo (Pearse et al. 1987, Hashimoto et al. 1991) and in vitro (Dissanayake et al. 1993) after direct exposure to UV irradiation, the results show that UV exposure causes keratinocytes to release a soluble factor or factors which promote cornification.

The possibility that this factor might be TGF- $\beta 1$ was investigated. TGF- $\beta 1$ is a known potent growth inhibitor for many cell types, including epithelial cells (Shipley et al. 1986, Pietenpol et al. 1990). TGF- $\beta 1$ has been reported to cause a reversible growth arrest of keratinocytes at the G1 phase of the cell cycle (Moses et al. 1987, Pietenpol et al. 1990). Arrest of cell growth seems to be a prerequisite for initiation of differentiation of keratinocytes (Fuchs 1990). It has also been reported that TGF- $\beta 1$ enhanced formation of cornified envelopes in normal human keratinocytes which were maintained in low calcium growth medium supplemented with epidermal growth factor (EGF) and this effect was not seen in the absence of EGF (Reiss \& Sartorelli 1987). The study by Matsumoto et al. (1990) reported, however, that TGF- $\beta 1$ enhanced formation of cornified envelopes in normal human keratinocytes in high calcium conditions, but inhibited this activity in low calcium media. The growth inhibitory effect of TGF- $\beta 1$ was seen in both high and low calcium conditions. Mansbridge \& Hanawalt (1988) reported that the synthesis of keratins 6 and 16, which are usually associated with hyperproliferation of keratinocytes, was increased after treatment with TGF- $\beta 1$, while synthesis of keratin 1 , associated with keratinocyte differentiation, was inhibited. In other studies, sodium butyrate enhanced cornified envelope formation in cultured human keratinocytes (Schmidt et al. 1989). Neutralising antibodies to TGF- $\beta 1$ effectively reduced this effect (Wang et al. 1992) while 


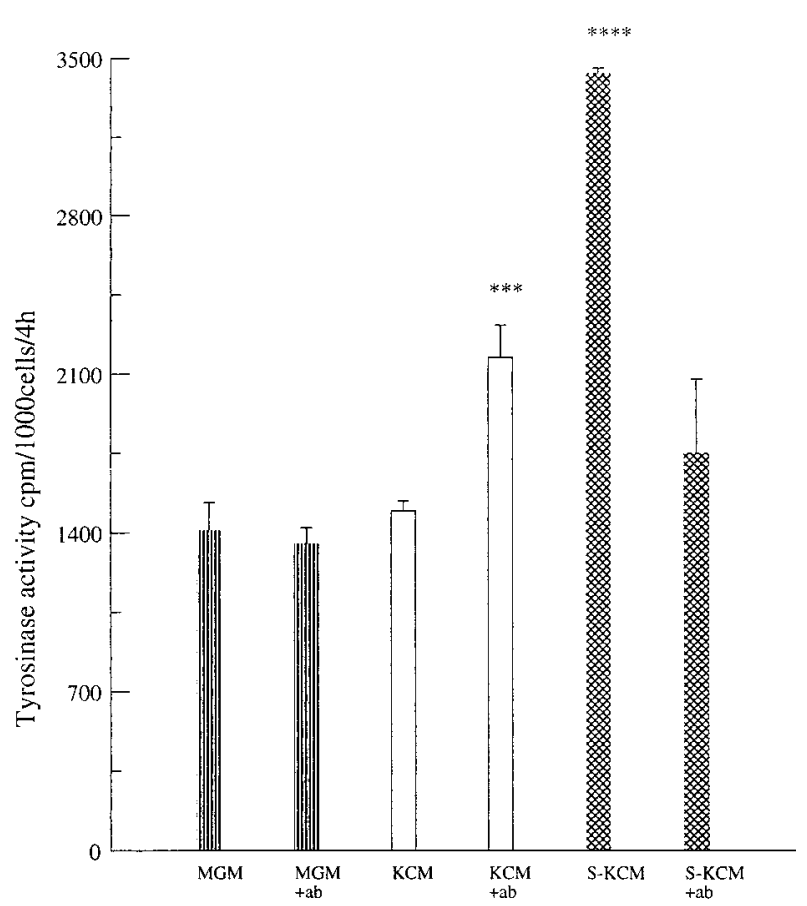

Figure 5 Neutralising effect of ACTH antibody on tyrosinase response in unirradiated melanocytes treated with S-KCM. Melanocytes were incubated with melanocyte growth medium (MGM), sham-irradiated conditioned medium (KCM) or solar-simulated conditioned medium (S-KCM) with or without $\mathrm{ACTH}$ antibody $(\mathrm{ab})$ for $36 \mathrm{~h}$ before the assay. Values are the means \pm S.D. of triplicate determinations. ${ }^{* *} P<0 \cdot 005$, $* * * * P<0 \cdot 001$ compared with cells incubated with conditioned medium from sham-irradiated cells or with melanocyte growth medium.

additional TGF- $\beta 1$ significantly enhanced the effect of sodium butyrate on keratinocyte differentiation. Even though there are some discrepancies among these reports, there are clear indications that TGF- $\beta 1$ is an important modulator of keratinocyte maturation.

In the present study, increased production of TGF- $\beta 1$ by keratinocytes after UV irradiation was demonstrated by immunofluorescence and by immunoassay. Furthermore, authentic TGF- $\beta 1$ mimicked the action of conditioned media collected from UV-irradiated cells on unexposed cells. This effect of UV-conditioned media on cornified envelope formation was abolished by a TGF- $\beta 1$ neutralising antibody. The results are consistent with the proposal that TGF- $\beta 1$ released by irradiated skin cells is at least partly responsible for the increased cornification which occurs after UV irradiation.

In relation to the other adaptive response to UV irradiation, detection of mRNA for pro-opiomelanocortin (POMC) has been reported in murine and human keratinocytes by Amornisiripanitch and Nordlund (1989), Schauer et al. (1994) and Wintzen et al. (1996) and in human melanocytes by Farooqui et al. (1993). Increased
POMC message levels in keratinocytes after UVR were reported by Wintzen et al. (1996). Regulatable secretion of $\alpha \mathrm{MSH}$ and ACTH (Schauer et al. 1994), a $30 \mathrm{kDa}$ POMC peptide as well as the products $\beta$-lipotropic hormone ( $\beta \mathrm{LPH})$ and $\beta$-endorphin (Wintzen et al. 1996) has been reported. To date, however, in terms of protein production, only $\alpha \mathrm{MSH}$ by A431 epidermal carcinoma cells (Schauer et al. 1994) and $\beta \mathrm{LPH}$ in human keratinocytes have been reported to be increased by UV exposure. We extended these observations to demonstrate that ACTH immunoreactivity is increased in irradiated keratinocytes. The conditioned media collected from irradiated keratinocytes and melanocytes stimulated tyrosinase activity of unirradiated melanocytes. We also showed that this effect was mimicked by addition of ACTH (1-39) and that the ACTH response was abolished by a neutralising antibody to ACTH. Furthermore, the antibody which binds to the 18-24 region of ACTH abolished the tyrosinase enhancing effect of conditioned media collected from irradiated keratinocytes. The ACTH antibody used in this study did not abolish the effect of MSH on melanocytes. These results are consistent with the proposal that after UV irradiation, keratinocytes release ACTH or an ACTH-like factor(s) that may be at least partly responsible for the subsequent pigmentary response. These results do not preclude the involvement of other mechanisms in generating the responses to UVR, such as the reported increase in MSH receptors in mouse melanoma cells after UVR (Bolognia et al. 1989).

The two-stage culture model used in the studies presented here, in which human skin cells receive direct UVR and their CM is then used to treat unirradiated skin cells, has proved useful to demonstrate the likely involvement of two paracrine factors - TGF- $\beta 1$ and ACTH - in the modification of skin cell activity after UVR. Further studies with this model and keratinocyte-melanocyte co-cultures are likely to provide additional insights into the mechanism of skin adaptation to UVR.

\section{Acknowledgements}

This work was supported by the NSW Cancer Council, the Leo and Jenny Foundation and the University of Sydney Cancer Research Fund. The authors thank Mr Gavin Greenoak of the Department of Animal Science, University of Sydney for access to the solar-simulator and for performing irradiance measurements. We are grateful to Dr Jean Joss of Macquarie University, Sydney for providing the antibody to ACTH.

\section{References}

Amornisiripanitch S \& Nordlund JJ 1989 Messenger RNA specific for POMC identified in murine epidermal cells. Journal of Investigative Dermatology 92 395A. 
Archambault M, Yaar M \& Gilchrest BA 1995 Keratinocytes and fibroblasts in a human skin equivalent model enhance melanocyte survival and melanin synthesis after ultraviolet irradiation. Journal of Investigative Dermatology 104 859-867.

Aubin F, Kripke ML \& Ullrich SE 1991 Activation of keratinocytes with psoralen plus UVA radiation induces the release of soluble factors that suppress delayed and contact hypersensitivity. Journal of Investigative Dermatology 97 995-1000.

Bolognia J, Murray M \& Pawelek J 1989 UVB-induced melanogenesis may be mediated through the MSH receptor system. Journal of Investigative Dermatology 92 651-656.

Chambon P, Dierich A, Gaub MP, Jakowlev S, Jongstra J, Krust A, LePennec JP, Oudet P \& Reudelhuber T 1984 Promoter elements of genes coding for proteins and modulation of transcription by estrogens and progesterone. Recent Progress in Hormone Research 40 $1-42$.

Colquhoun D 1971 Lectures on Biostatistics - An Introduction to Statistics with Applications in Biology and Medicine, p 41. Oxford: Clarendon Press.

Dissanayake NS, Greenoak G \& Mason RS 1993 Effects of UV irradiation on human skin-derived epidermal cells in vitro. Journal of Cellular Physiology 157 119-127.

Farooqui JZ, Medrano EE, Abdel-Malek Z \& Nordlund J 1993 The expression of proopiomelanocortin and various POMC-derived peptides in mouse and human skin. Annals of the New York Academy of Sciences $\mathbf{6 8 0} 508-510$.

Fitzpatrick TB 1986 Ultraviolet-induced pigmentary changes: benefits and hazards. Current Problems in Dermatology 15 25-38.

Fuchs E 1990 Epidermal differentiation: the bare essentials. Journal of Cell Biology 111 2807-2814.

Gange RW, Blackett AD, Matzinger EA, Sutherland BM \& Kochevar IE 1985 Comparative protection efficiency of UVA and UVBinduced tan against erythema and formation of endonuclease sensitive sites in DNA by UVB in human skin. Journal of Investigative Dermatology 85 362-364.

Gilchrest BA, Zhai S, Eller MS, Yarosh DB \& Yaar M 1993 Treatment of human melanocytes and S91 melanoma cells with the DNA repair enzyme T4 endonuclease $\mathrm{V}$ enhances melanogenesis after ultraviolet irradiation. Journal of Investigative Dermatology 101 666-672.

Gordon PR \& Gilchrest B 1989 Human melanogenesis is stimulated by diacylglycerol. Journal of Investigative Dermatology 93 700-702.

Gordon PR, Mansur CP \& Gilchrest BA 1989 Regulation of human melanocyte growth, dendricity and melanization by keratinocytederived factors. Journal of Investigative Dermatology 92 565-572.

Halaban R, Langdon R, Birchall N, Cuono C, Baird A, Scott G, Moellmann G \& McGuire J 1988 Paracrine stimulation of melanocytes by keratinocytes through basic fibroblast growth factor. Annals of the New York Academy of Sciences 548 180-190.

Hashimoto Y, Ohkuma N \& Iizuka H 1991 Reduced superoxide disumutase activity in UVB-induced hyperproliferative pig epidermis. Archives of Dermatological Research 283 317-320.

Joss JM, Beshaw M, Williamson S, Trimble J \& Dores RM 1990 The adenohypophysis of the Australian lungfish, Neoceratodus forsteri - an immunocytological study. General and Comparative Endocrinology $\mathbf{8 0}$ 274-287.

Kock A, Schwarz T, Kirnbauer R, Urbanski A, Perry P, Ansel JC \& Luger TA 1990 Human keratinocytes are source for tumor necrosis factor $\alpha$ : evidence for synthesis and release upon stimulation with endotoxin or ultraviolet light. Journal of Experimental Medicine 172 1609-1614.

Kramer M, Sachsenmaier C, Herrlich P \& Rahmsdorf HJ 1993 UV irradiation-induced interleukin-1 and basic fibroblast growth factor synthesis and release mediate part of the UV response. Journal of Biological Chemistry 268 6734-6741.

Kratz G, Haegerstrand A \& Dalsgaard CJ 1991 Conditioned medium from cultured human keratinocytes has growth stimulatory properties on different human cell types. Journal of Investigative Dermatology 97 1039-1043.
Kupper TS, Min K, Sehgal P, Mizutani H, Birchall N \& Ray A 1989 Production of IL-6 by keratinocytes: implication of epidermal inflammation and immunity. Annals of the New York Academy of Sciences 557 454-465.

Luger TA 1989 Epidermal cytokines. Acta Dermato-Venereologica Supplementum 151 61-76.

McLane JA, Katz M \& Abdelkader N 1990 Effect of 1,25-dihydroxyvitamin D3 on human keratinocytes grown under different culture conditions. In Vitro Cellular and Developmental Biology 26 379-387.

McLeod SD, Smith C \& Mason RS 1995 Stimulation of tyrosinase in human melanocytes by pro-opiomelanocortin-derived peptides. Journal of Endocrinology 146 439-447.

Mansbridge JN \& Hanawalt PC 1988 Role of transforming growth factor $\beta 1$ in the maturation of human epidermal keratinocytes. Journal of Investigative Dermatology 90 336-341.

Matsumoto K, Hashimoto K, Hashiro M, Yoshimasa H \& Yoshikawa K 1990 Modulation of growth and differentiation in normal human keratinocytes by transforming growth factor $\beta$. Journal of Cellular Physiology 145 95-101.

Morison WL 1985 What is the function of melanin? Archives of Dermatology 121 1160-1163.

Moses HL, Coffey RJ Jr, Leof EB, Lyons RM \& Keski-Oja J 1987 Transforming growth factor $\beta$ regulation of cell proliferation. Journal of Cellular Physiology Supplement 5 1-7.

Nelson AE, Namkung HJ, Patava J, Wilkinson MR, Chang AC-M, Reddel RR, Robinson BG \& Mason RS 1996 Characteristics of tumor cell bioactivity in oncogenic osteomalacia. Molecular and Cellular Endocrinology 124 17-23.

Oka M, Ichihashi M \& Chakraborty AK 1996 Enhanced expression of protein kinase $\mathrm{C}$ subspecies in melanogenic compartments in B16 melanoma cells by UVB or MSH. Journal of Investigative Dermatology 106 377-378.

Park HY, Russakovsky V, Ohno S \& Gilchrest BA 1993 The $\beta$ isoform of protein kinase $\mathrm{C}$ stimulates human melanogenesis by activating tyrosinase in pigment cells. Journal of Biological Chemistry 268 11742-11749.

Pawelek JM, Chakraborty AK, Osber MP \& Bolognia JL 1992 Ultraviolet light and pigmentation of the skin. Cosmetics and Toiletries 107 61-68.

Pearse AD, Gaskell SA \& Marks R 1987 Epidermal changes in human skin following irradiation with either UVB or UVA. Journal of Investigative Dermatology 88 83-87.

Pietenpol JA, Holt JT, Stein RW \& Moses HL 1990 Transforming growth factor $\beta 1$ suppression of $\mathrm{c}-\mathrm{myc}$ gene transcription: role in inhibition of keratinocyte proliferation. Proceedings of the National Academy of Sciences of the USA 87 3758-3762.

Pomerantz SH 1966 The tyrosine hydroxylase activity of mammalian tyrosinase. Journal of Biological Chemistry 241 161-168.

Ranson M, Posen S \& Mason RS 1988 Extracellular matrix modulates the function of human melanocytes but not melanoma cells. Journal of Cellular Physiology 136 281-288.

Reiss M \& Sartorelli AC 1987 Regulation of growth and differentiation of human keratinocytes by type $\beta$ transforming growth factor and epidermal growth factor. Cancer Research $\mathbf{4 7}$ 6705-6709.

Robert C, Muel B, Benoit A, Dubertret L, Sarasin A \& Stary A 1996 Cell survival and shuttle vector mutagenesis induced by ultraviolet A and ultraviolet B radiation in a human cell line. Journal of Investigative Dermatology 106 721-728.

Rosdahl IK 1979 Local and systemic effects on the epidermal melanocyte population in UV-irradiated mouse skin. Journal of Investigative Dermatology 73 306-309.

Schauer E, Trautinger F, Kock A, Schwarz A, Bhardwaj R, Simon M, Ansel JC, Schwarz T \& Luger TA 1994 Proopiomelanocortinderived peptides are synthesised and released by human keratinocytes. Journal of Clinical Investigation 93 2258-2262. 
Schmidt R, Cathelineau C, Cavey MT, Dionisius V, Michel S, Shroot B \& Reichert U 1989 Sodium butyrate selectively antagonizes the inhibitory effect of retinoids on cornified envelope formation in cultured human keratinocytes. Journal of Cellular Physiology 140 281-287.

Shipley GD, Pittelkow MR, Wille JJ Jr, Scott RE \& Moses HL 1986 Reversible inhibition of normal human prokeratinocyte proliferation by type $\beta$ transforming growth factor-growth inhibitor in serum free medium. Cancer Research 46 2068-2071.

Stierner U, Rosdahl I, Augustsson A \& Kagedal B 1989 UVB irradiation induces melanocyte increase in both exposed and shielded human skin. Journal of Investigative Dermatology 92 561-564.

Swartz RP 1984 Role of UVB-induced serum factor(s) in suppression of contact hypersensitivity in mice. Journal of Investigative Dermatology 83 305-310.
Szabo G, Blog FB \& Kornhauser A 1982 Toxic effect of ultraviolet light on melanocytes: use of animal models in pigment research. Journal of National Cancer Institute 69 245-250.

Wang G, Higgins PJ, Gannon M \& Staiano-Coico L 1992

Transforming growth factor- $\beta 1$ acts coopereratively with sodium n-butyrate to induce differentiation of normal human keratinocytes. Experimental Cell Research 198 27-30.

Wintzen M, Yaar M, Burbach JPH \& Gilchrest BA 1996 Proopiomelanocortin gene product regulation in keratinocytes. Journal of Investigative Dermatology 106 673-678.

Received 16 December 1996

Revised manuscript received 26 May 1998 Accepted 9 June 1998 